\title{
Controlled sub-10-nanometer poly( $N$-isopropyl-acrylamide) layers grafted from silicon by atom transfer radical polymerization
}

\author{
Andreas S. Schulz ${ }^{1,2,3}$ (D) । Hubert Gojzewski ${ }^{1}$ | Jurriaan Huskens ${ }^{2}$ | Willem L. Vos ${ }^{3}$ । \\ G. Julius Vancso ${ }^{1}$
}

${ }^{1}$ Materials Science and Technology of Polymers (MTP), MESA+ Institute for Nanotechnology, University of Twente, PO Box 217, 7500 AE Enschede, The Netherlands

2 Molecular NanoFabrication (MNF), MESA+ Institute for Nanotechnology, University of Twente, PO Box 217, 7500 AE Enschede, The Netherlands

${ }^{3}$ Complex Photonic Systems (COPS), MESA+ Institute for Nanotechnology, University of Twente, PO Box 217, 7500 AE Enschede, The Netherlands

\section{Correspondence}

G. Julius Vancso, Materials Science and Technology of Polymers (MTP), MESA+ Institute for Nanotechnology, University of Twente, PO Box 217, 7500 AE Enschede, The Netherlands.

Email: g.j.vancso@utwente.nl

\section{Funding information}

Netherlands Organisation for Scientific Research NWO
Surface-initiated atom transfer radical polymerization (SI-ATRP) was used to graft poly(Nisopropylacrylamide) (PNIPAM) brush layers with a controllable thickness in the 10-nm range from silicon substrates. The rate of polymerization of $\mathrm{N}$-isopropylacrylamide was tuned by the $[\mathrm{Cu}(\mathrm{II})]_{0} /[\mathrm{Cu}(\mathrm{I})]_{0}$ ratio between the deactivating and activating species. The polymer layer thickness was characterized by atomic force microscopy (AFM) and ellipsometry. PNIPAM layers with a dry thickness between 5.5 and $16 \mathrm{~nm}$ were obtained. Time-of-flight secondary ion mass spectrometry (ToF-SIMS) confirmed that the chemical structure is PNIPAM brushes. Analysis of the AFM data showed that our procedure leads to polymer grafts in the "mushroom-to-brush" transition regime.

\section{KEYWORDS}

atom transfer radical polymerization, poly( $\mathrm{N}$-isopropylacrylamide), polymer brushes, time-of-flight secondary ion mass spectrometry (ToF-SIMS)

\section{I INTRODUCTION}

Polymer grafts attached to various substrates have been used with great success to engineer both surface and interfacial properties of the material to which they are anchored. Brushes, a frequently employed form of surface bound polymer grafts, possess chains in a stretched conformation in good solvents due to molecular crowding. This crowding dominates the structure, and thus the properties of the grafted layer if the attachment distance between neighboring chains substantially reaches the unperturbed chain diameter in good solvents. ${ }^{1}$ Polymer brushes have found use in a broad range of applications, ${ }^{2-7}$ such as altering the wetting behavior of surfaces, ${ }^{8}$ forming ion transport barriers, ${ }^{9,10}$ fabricating protein microarrays, ${ }^{11}$ in antibody immobilization, ${ }^{12}$ in tissue engineering, ${ }^{13}$ and for manipulating nanoparticles. ${ }^{14}$ Our interest is to covalently attach quantum dot nanocrystals to the ends of polymer brushes, to control the position of such emitters in the 10-nm range so as to control their spontaneous emission and energy transfer rates. ${ }^{15-17}$ Because silicon yields powerful nanophotonic structures, even planar, we choose it as a substrate. Because position tunability is a desirable feature, we choose poly(N-isopropyl-acrylamide) (PNIPAM) because it is a stimulusresponsive polymer material ${ }^{6}$ that allows to tune its thickness by swelling in a suitable solvent or by temperature. ${ }^{18,19}$

The preparation of relatively smooth and homogeneous polymer brush layers by surface-initiated atom transfer radical polymerization (SI-ATRP) is known to be well controlled. ${ }^{20}$ SI-ATRP is a versatile method to tune the layer thickness with a narrow distribution in molar mass of the grafted chains., ${ }^{51-28}$ However, grafting thin PNIPAM brushes from a surface is challenging due to the fast polymerization rate of NIPAM in aqueous media. ${ }^{29}$ Reproducible procedures for obtaining brush layers of PNIPAM with thicknesses in the sub-10-nm range (hereinafter ultrathin brush layers) in the dry state are sparse for dense ATRP-initiator concentrations on the surface.

One possibility to achieve a better control is provided by slowing down the polymerization rates. The rate of ATRP essentially depends on the rate constant of propagation of the polymerization, on the 
concentrations of the monomer and the growing radicals. In ATRP, the radical concentration depends on the equilibrium constant of the reaction, and on the concentrations of the dormant species, activators (eg, $\left.\mathrm{Cu}^{\prime}\right)$, and deactivators (eg, $\left.\mathrm{Cu}^{\prime \prime}\right)$. For example, Zhang et al. demonstrated experimentally that the $[\mathrm{Cu}(\mathrm{II})]_{0} /[\mathrm{Cu}(\mathrm{I})]_{0}$ ratio, tuned by the addition of deactivating $\mathrm{Cu}(\mathrm{II})$ to the initial polymerization reaction mixture, has strong effects on the kinetics of ATRP. ${ }^{30}$ In parallel with slowing down the polymerization rate, the addition of deactivating $\mathrm{Cu}(\mathrm{II})$ to the ATRP reaction mixture also improves the control over the molar mass and the polydispersity. ${ }^{31}$ To our knowledge, tuning the $[\mathrm{Cu}(\mathrm{II})]_{0} /[\mathrm{Cu}(\mathrm{I})]_{0}$ ratio has so far not been used to obtain PNIPAM layers with thicknesses in the 10-nm range. One of the challenges to control the ATRP of acrylamide monomers like NIPAM is caused by catalyst inactivation. ${ }^{32-34}$ Due to complexation of copper by the growing polymer chain and the monomer, and due to the displacement of the terminal halogen atom by the nucleophilic amide group, the system can become deactivated. Kizhakkedathu et al. polymerized PNIPAM with a well-defined thickness from polystyrene (PS) latex particles. ${ }^{35}$ Fulghum et al. reported the polymerization of ultrathin PNIPAM brushes on top of a membrane surface. ${ }^{36}$ Alem et al. reported the growth of PNIPAM brushes from nanopore walls of poly(ethyleneterephthalate) membranes. ${ }^{37}$ Malham and Bureau reported a procedure to graft PNIPAM layers by reducing the initial ATRP initiator coverage. ${ }^{38}$ For a $10-\mathrm{nm}$ thin PNIPAM layer, they reported a low grafting density of 0.02 chains per $\mathrm{nm}^{2}$. Cimen and Caykara presented oligoNIPAM brushes with $-\mathrm{OH}$ and $-\mathrm{COOH}$ end-groups. ${ }^{39}$ Pomorska et al showed that the layer thickness can be influenced by the solvent composition between water and methanol. ${ }^{40}$ However, a precise control over the layer thickness in the 10 -nm range was not provided.

Here, we present the fabrication of ultrathin PNIPAM layers with thicknesses in the 10-nm range grafted from silicon substrates via SIATRP by varying the $[\mathrm{Cu}(\mathrm{II})]_{0} /[\mathrm{Cu}(\mathrm{I})]_{0}$ ratio. The initiator density on the substrates was kept constant during the procedures. We aimed for a high initiator density to graft dense polymer chains from the substrate. The polymer brush thickness was controlled by the deactivating copper(II) species to slow down the polymerization rate. Our approach leads to smooth and homogeneous ultrathin PNIPAM polymer layers as confirmed by ellipsometry, time-of-flight secondary ion mass spectrometry (ToF-SIMS), and atomic force microscopy (AFM).

\section{2 | EXPERIMENTAL}

\section{1 | Sample fabrication}

The chemical process followed in this study is summarized in Scheme 1a. A typical sample was fabricated in 3 main steps (see supplement). First, silicon substrates were cut into pieces of $1.2 \times 1.2 \mathrm{~cm}$, cleaned with a Piranha solution, extensively rinsed with water and ethanol (see Scheme 1b), and dried in a nitrogen stream. In the second step, the coupling agent 3-(chlorodimethylsilyl)propyl 2bromo-2-methylpropionate 1 was reacted with the cleaned silicon substrates by chemical vapor deposition (CVD). The initiator coverage was not varied in this study. Thirdly, the resulting highly hydrophobic

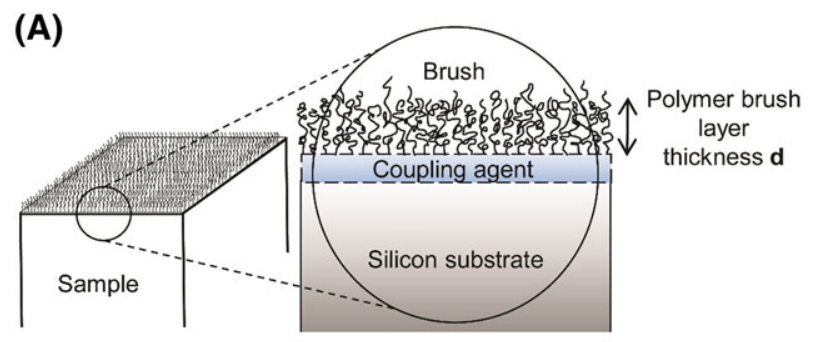

(B)
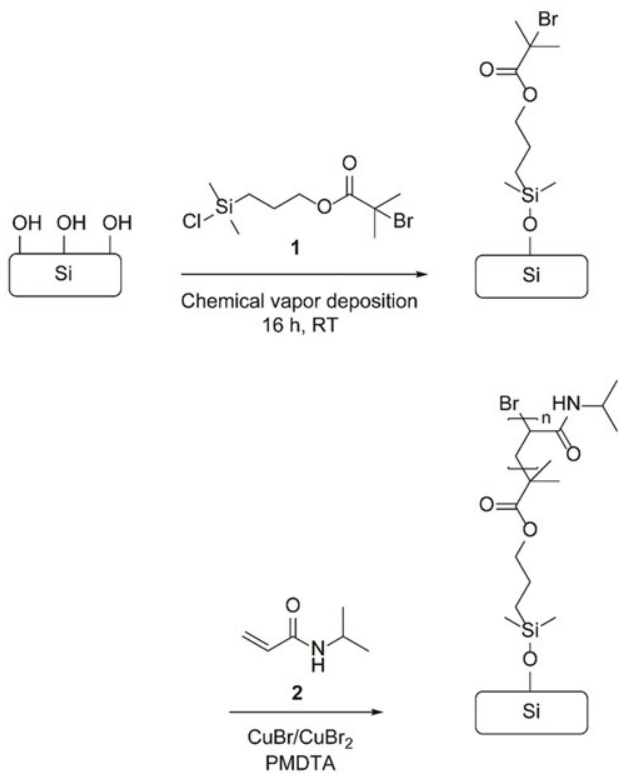

SCHEME 1 (a) Schematic representation of a polymer brush layer with thickness $d$ on a silicon substrate. On the left-hand side, the overall view of the sample is shown. The area within the black circle is enlarged on the right. The surface of the silicon substrate is activated by a coupling agent (atom transfer radical polymerization [ATRP] initiator), shown in light blue. The individual polymer chains form the polymer brush structure. (b) General reaction schemes to anchor the ATRP initiator 1 to silicon substrate and to perform ATRP of NIPAM 2 [Colour figure can be viewed at wileyonlinelibrary.com]

surface was used to graft short PNIPAM chains from the initiator molecules. The polymerization solution consisted of the monomer NIPAM 2, the ligand, and the catalyst. $\mathrm{Cu}(\mathrm{I})$ and $\mathrm{Cu}(\mathrm{II})$ bromide were used to form transition-metal complexes with the ligand $N, N, N^{\prime}, N^{\prime}, N^{\prime \prime}$ pentamethyldiethylenetriamine (PMDTA). $\mathrm{Cu}(\mathrm{II})$ bromide was added to slow down the polymerization rate. The molar ratio of $\left[\mathrm{Cu}(\mathrm{II}) \mathrm{Br}_{2}\right] /$ $[\mathrm{Cu}(\mathrm{I}) \mathrm{Br}]$ was varied between $7 \%$ and $10 \%$. Below a $[\mathrm{Cu}(\mathrm{II})]_{0} /[\mathrm{Cu}(\mathrm{I})]_{\mathrm{o}}$ ratio of $7 \%$, we observed that the polymerization is too fast and thus not reproducible. Beyond a $[\mathrm{Cu}(\mathrm{II})]_{0} /[\mathrm{Cu}(\mathrm{I})]_{0}$ ratio of $10 \%$, we observed an increasing difficulty to dissolve the $\mathrm{Cu}(\mathrm{II})$ bromide. Four different polymerization batches were made to study the effect of $\mathrm{Cu}(\mathrm{II})$ on the reaction kinetics. For each batch, 3 samples were synthesized and characterized. Following completion of the polymerization, the samples were extensively cleaned with Milli-Q water and with ethanol to remove non-reacted monomer, metal-complex, and remaining catalyst residues. The samples were finally dried in a nitrogen stream to obtain silicon substrates with thin poly( $\mathrm{N}$-isopropylacrylamide) polymer brush films. The molecular characterization of polymer brush surfaces remains a challenging scientific task. ${ }^{41}$ To characterize the PNIPAM layers, we employed time-of-flight secondary ion mass 
spectrometry, atomic force microscopy, and ellipsometry. ToF-SIMS was used to analyze the chemical composition of the polymer brush film. AFM was used to study the morphology and the thickness of the polymer brush on the silicon substrate in both dry and wet states. Furthermore, AFM measurements in water were performed to derive the grafting density of the brushes. Ellipsometry was used to analyze the polymer layer thickness and to provide complementary information to AFM.

\section{2 | Ellipsometry}

The dry thickness of a surface-grafted PNIPAM film was determined by a variable-angle spectroscopic ellipsometer (VASE ellipsometer base model, LOT Oriel GmbH, Darmstadt, Germany) at 3 different angles of incidence $\left(65^{\circ}, 70^{\circ}\right.$, and $\left.75^{\circ}\right)$ at room temperature. The thickness was determined via the analysis of a $3-\operatorname{layer}\left(\mathrm{Si} / \mathrm{SiO}_{2} / \mathrm{PNIPAM}\right)$ model with known thicknesses of the $\mathrm{Si}$ and $\mathrm{SiO}_{2}$ layers and known refractive indices of the $\mathrm{Si}$ and $\mathrm{SiO}_{2}$ layers (software WVASE32, LOT Oriel $\mathrm{GmbH}$, Darmstadt, Germany). It was assumed that the polymer has a refractive index of $1.47 .^{42}$

\section{3 | Time-of-flight secondary ion mass spectrometry}

The ToF-SIMS measurements were performed on a ToF-SIMS IV-100 (ION-TOF GmbH, Münster, Germany) located at the University of Siegen that was equipped with a bismuth liquid metal ion gun (LMIG). $\mathrm{A} \mathrm{Bi}_{3}{ }^{+}$ primary beam at $25 \mathrm{keV}$ was used in a high-current bunched mode to measure spectra for positively charged fragments with a pulse width of $0.15 \mathrm{~ns}$. The target current was set to $0.2 \mathrm{pA}$. All spectra were taken from an area of $100 \times 100 \mathrm{um}^{2}(128 \times 128$ pixels). Positive ion spectra were internally mass calibrated using $\mathrm{CH}_{3}{ }^{+}, \mathrm{C}_{2} \mathrm{H}_{5}{ }^{+}$, and $\mathrm{C}_{3} \mathrm{H}_{7}{ }^{+}$peaks.

\subsection{Atomic force microscopy}

AFM measurements were performed in tapping (dry brush thickness and roughness) and contact (wet brush thickness) modes using the Multimode 8 AFM retrofitted with the NanoScope $V$ controller and the JV vertical engage scanner (Bruker, Santa Barbara, CA, USA). In tapping mode, a commercially available high-frequency $(320 \mathrm{kHz})$ silicon cantilevers (model NCH, NanoWorld, Switzerland) with a nominal spring constant of $42 \mathrm{~N} / \mathrm{m}$ and a nominal tip radius of $8 \mathrm{~nm}$ (shape of polygon based pyramid) were used. The scanning was performed at a scan rate of $0.5 \mathrm{~Hz}$ with the ratio of set point amplitude to free oscillation amplitude of approximately 0.75 .

For contact mode, custom-made colloidal probes were manufactured using a soft cantilever (TL-CONT, Nanosensors, Switzerland; nominal spring constant of $0.2 \mathrm{~N} / \mathrm{m}$ ) and PS bead (Duke Standards 4205A, Thermo Scientific, USA; diameter of $5 \mu \mathrm{m}$ ), to induce high contact area with the brush, and thus to reduce the applied contact pressure. The colloidal probe preparation contained the following steps: (1) PS particles were diluted in water and drop-coated on a freshly cleaved mica surface, then dried with nitrogen; (2) individual beads were attracted from mica by a tungsten wire (World Precision Instruments, Inc.) controlled by a home-made micromanipulator under an optical microscope; (3) the tungsten wire was chemically etched at $30 \mathrm{~V}$ in $1 \mathrm{M} \mathrm{KOH}$ water solution until the end diameter was of approximately 10 to $15 \mu \mathrm{m}$ in order to transfer individual colloids; (4) the wire was immersed in ethanol and dried under nitrogen to induce a proper wire-colloid capillary adhesion; (5) the beads were adhered using a UV-cured glue (Optical Adhesive 81, Norland Products, Inc.) to the end of the cantilever and photocured using high intensity UV lamp (Hamamatsu LC8, type 02A) for 3 minutes in air. The quality of the colloidal probes was carefully checked by optical and scanning electron microscopy imaging. The contact mode imaging with colloidal probes was conducted in water, which was injected via a syringe to the liquid cell; the system was alone to attain equilibrium for 20 minutes. The cantilever spring constant was determined in water by the thermal tuning method. ${ }^{43,44}$ The imaging was performed at a scan rate of $0.3 \mathrm{~Hz}$ with a load force of $1.6 \mathrm{nN}$, which corresponds to the lowest possible force value that still allowed us to obtain stable images with a clear step height profile in the brush.

All images, either for tapping or contact mode, were collected at a temperature of $21^{\circ} \mathrm{C}$. The temperature was strictly controlled; fluctuations were smaller than $0.2^{\circ} \mathrm{C}$. Image processing and data analysis were conducted with the NanoScope (ver. 8.15) and the NanoScope Analysis software (ver. 1.7), respectively. To quantify the average height variation, a step height analysis was performed.

\section{3 | RESULTS AND DISCUSSION}

\section{1 | Effect of $[\mathrm{Cu}(\mathrm{II})]_{0} /[\mathrm{Cu}(\mathrm{I})]_{0}$ ratio on brush thickness}

Figure 1 shows the averaged dry polymer thickness $d_{\mathrm{e}}$ obtained as a function of the $[\mathrm{Cu}(\mathrm{II})]_{0} /[\mathrm{Cu}(\mathrm{I})]_{\mathrm{O}}$ ratio. Table 1 presents the dry thickness for each substrate measured by ellipsometry. Because our procedure leads to ultrathin brush layers, ellipsometry reaches its limits to obtain a reliable value for the layer thickness. ${ }^{45}$ To confirm the

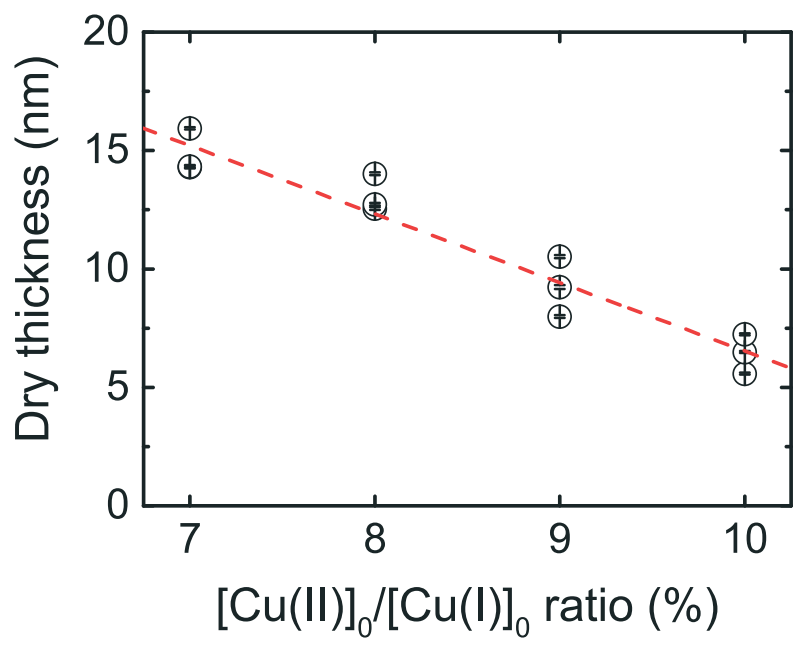

FIGURE 1 Brush thickness $d_{\mathbf{e}}$ of the PNIPAM layers, determined from ellipsometry, as a function of the $[\mathrm{Cu}(\mathrm{II})]_{0} /[\mathrm{Cu}(\mathrm{I})]_{0}$ ratio for a polymerization time of $30 \mathrm{~min}$ in water/methanol $(50 \%, \mathrm{v} / \mathrm{v})$. Black circles present the average thickness for 1 substrate. The dashed red line is a guide to the eye. With increasing $[\mathrm{Cu}(\mathrm{II})]_{0} /[\mathrm{Cu}(\mathrm{I})]_{0}$ ratio, the polymerization rate of grafting PNIPAM chains from the Si surface decreases [Colour figure can be viewed at wileyonlinelibrary.com] 
TABLE 1 Dry thickness $d_{\mathrm{e}}$ of PNIPAM brushes measured by ellipsometry

\begin{tabular}{llll}
$\begin{array}{l}\text { Thickness } \mathrm{nm}, 7 \% \\
{[\mathrm{Cu}(\mathrm{II})]_{0} /[\mathrm{Cu}(\mathrm{I})]_{0}}\end{array}$ & $\begin{array}{l}\text { Thickness } \mathrm{nm}, 8 \% \\
{[\mathrm{Cu}(\mathrm{II})]_{0} /[\mathrm{Cu}(\mathrm{I})]_{0}}\end{array}$ & $\begin{array}{l}\text { Thickness nm, } 9 \% \\
{[\mathrm{Cu}(\mathrm{II})]_{0} /[\mathrm{Cu}(\mathrm{I})]_{0}}\end{array}$ & $\begin{array}{l}\text { Thickness nm, } 10 \% \\
{[\mathrm{Cu}(\mathrm{II})]_{0} /[\mathrm{Cu}(\mathrm{I})]_{0}}\end{array}$ \\
\hline $14.30 \pm 0.05$ & $12.55 \pm 0.06$ & $7.99 \pm 0.06$ & $5.58 \pm 0.04$ \\
$14.33 \pm 0.05$ & $12.74 \pm 0.06$ & $10.52 \pm 0.06$ & $6.49 \pm 0.04$ \\
$15.94 \pm 0.05$ & $14.02 \pm 0.06$ & $9.24 \pm 0.08$ & $7.24 \pm 0.04$
\end{tabular}

thickness values determined by ellipsometry, we studied our samples with AFM to derive the polymer layer thickness with a different analytical method. Because both methods are based on different physics and have a completely different error margin, a direct comparison should be interpreted as an indication only. Figure 1 shows a decreasing linear trend with increasing $[\mathrm{Cu}(\mathrm{II})]_{0} /[\mathrm{Cu}(\mathrm{I})]_{0}$ ratio. Thus, these data reveal that the $[\mathrm{Cu}(\mathrm{II})]_{0} /[\mathrm{Cu}(\mathrm{I})]_{0}$ ratio controls the thickness of the grafted layer. In the ATRP reaction, $\mathrm{Cu}(\mathrm{I})$ becomes oxidized to $\mathrm{Cu}(\mathrm{II})$ by extracting a halide atom from the dormant species. Adding more $\mathrm{Cu}(\mathrm{II})$ halide shifts the equilibrium towards the dormant state, by enhancing the concentration of alkyl halides $\left(P_{n} X\right)$, thus slowing down the ATRP reaction rate. The thickness range accessible by the procedure described here is limited by the solubility of $\mathrm{Cu}(\mathrm{II})$ bromide in the water/methanol mixture, down to $d \approx 6 \mathrm{~nm}$.

\subsection{Chemical composition}

The chemical composition of the polymer films was investigated by ToF-SIMS, which is a surface-sensitive method to characterize thin films, where the small primary ion beam removes a thin layer of the surface. ${ }^{46}$ Several articles reported the use of ToF-SIMS to characterize thin films. ${ }^{47-49}$ The analysis of the chemical composition via ToFSIMS was performed as the method can provide information on the molecular structure of a thin film in a very sensitive manner. The polymer layers were directly measured at the substrate to which they are anchored.

In addition, ToF-SIMS offers the possibility to obtain an intensity "map" for different fragments. We use the term map to define an area scan on the substrate to verify the compositional homogeneity. With the help of the intensity map, it is possible to assess whether the fragments are formed homogeneously across the whole scan area; some representative examples are shown in the supplementary information (SI: Figures S6-S9). These data show that the layers were homogeneous across the substrate.

From the ToF-SIMS measurements, the positively charged fragments formed in the surface ionization process were analyzed. The measured counts per fragment as a function of mass are shown in Figure 2A. To clarify the important mass peaks, we added the corresponding masses of the fragments to the plot. We observed 6 main fragment masses besides lower intensity counts for impurities, or for other fragments formed during the measurement. Starting from the lowest fragment mass, distinct peaks were observed at $m / z=27,43$, $55,58,72$, and 114 . Because similar mass patterns have been reported in the literature for PNIPAM, we used these results as a starting point to obtain peak assignment for PNIPAM grafts studied here. ${ }^{50-54} \mathrm{We}$ propose the assignment of the corresponding chemical structures of these most important fragments in Figure 2B. The characteristic peaks observed at $43 \mathrm{~m} / \mathrm{z}\left(\mathrm{C}_{3} \mathrm{H}_{7}{ }^{+}\right.$, isopropyl) and at $114 \mathrm{~m} / \mathrm{z}$ correspond to 1 monomer unit of NIPAM. The other measured fragments are in good agreement with the calculated masses; apparently, no trace of the initiator could be detected. In Figure 2C, we plot the counts of the individual positively charged fragments against the $[\mathrm{Cu}(\mathrm{II})]_{0} /[\mathrm{Cu}(\mathrm{I})]_{0}$ ratio. Each bar represents the counts for 1 specific fragment mass. We show 6 counts for the 6 most important fragments per batch. Notably, the number of counts was similar for the 4 batches. By analyzing the fragment intensities of the 6 main fragments from the $4[\mathrm{Cu}(\mathrm{II})]_{0} /[\mathrm{Cu}(\mathrm{I})]_{\mathrm{O}}$ ratios we used to graft PNIPAM from the surface, we can unambiguously identify the films to be PNIPAM.

\subsection{Brush characterization with AFM}

To demonstrate that our procedure leads to relatively homogeneous sub-10-nm layers, we used AFM tapping mode to study the thickness of the functionalized substrates. The grafted films were scratched by a teflon-coated tweezer to remove the polymer from the substrate and allow for direct thickness and roughness determination by surface imaging. Brush thickness values were measured for dry (this section) and wet (see Grafting density section) grafted films.

In Figure 3A, an AFM height image of one of the thinnest sample is shown. The left side of the image represents the scratched area (dark color), whereas the right side-the surface of the brush film (bright color). The phase images (not shown) confirmed a successful material removal from the silicon wafer (high contrasted bi-phase).

A representative cross section of the scratched sample is presented in Figure 3B. The lowest point addresses the bare silicon wafer; some profile variation is visible due to the residual polymer content. The highest point in the plot addresses the brush surface; a characteristic pile-up (peak profile) is also visible as a result of material plowing. By measuring the step height, the polymer brush thickness was determined. Several samples have been analyzed, and random positioned cross section has been performed to determine the thickness of the dry film; the distribution is plotted as histogram in Figure 3C. The data were fitted with a Gaussian distribution. The polymer layer thickness $d$ varied between 5.3 and $6 \mathrm{~nm}$ with a mean of $5.5 \mathrm{~nm} \pm 0.3 \mathrm{~nm}$.

Additionally, we analyzed the root mean square roughness $R_{q}$ for the polymer brush surface by scanning areas of different sizes (see Figure 4). We observe a very small increase of $R_{q}$ for the polymer brush layer compared with the bare silicon substrate. A slightly increasing trend can be observed by comparing the polymer brush layers with a silicon substrate, while the brush surface shows a "slowing down" of the roughness increase with increasing scan size. We assume that the roughness for a dried polymer film is higher than for a bare silicon substrate due to a statistical variation of monomer attachment to the surface, and due to the random conformation of the grafted polymer molecules. The underlying ATRP initiator has a slight impact on the roughness as well. Additionally, the kinetics of the drying process 
(A)

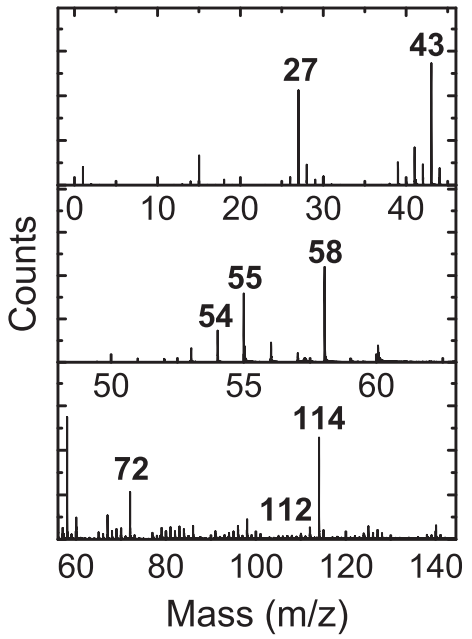

(B)<smiles>[CH+]=C</smiles><smiles>CCCC</smiles>

$27.02 \mathrm{~m} / \mathrm{z}$

$43.05 \mathrm{~m} / \mathrm{z}$<smiles>C[C+]C=O</smiles><smiles>CC(C)[NH3+]</smiles>

$56.03 \mathrm{~m} / \mathrm{z}$

$58.07 \mathrm{~m} / \mathrm{z}$<smiles>C[CH+]NC=O</smiles>

$72.04 \mathrm{~m} / \mathrm{z}$<smiles>CCC(=O)N[C+](C)C</smiles>

$114.09 \mathrm{~m} / \mathrm{z}$
(C)

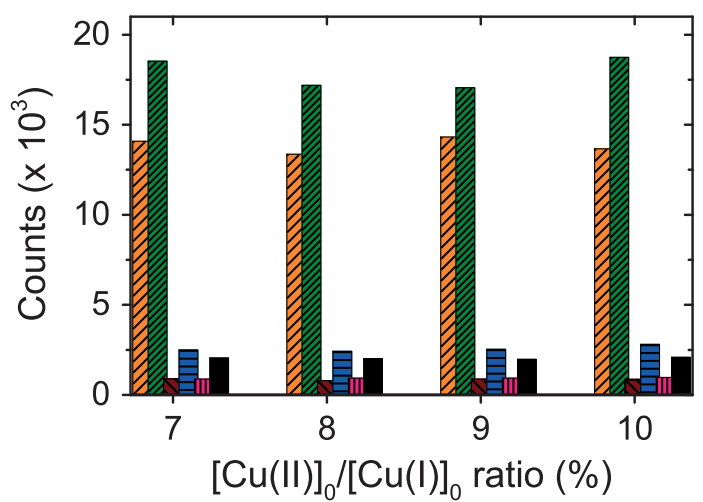

FIGURE 2 (A) Positively charged fragments of the PNIPAM layers on silicon measured by ToF-SIMS. The scale of the $y$-axis of the 3 graphs is in counts. Black bars represent the measured fragment masses; (B) fragments expected from literature (for references see text), the corresponding chemical structures of the fragments are shown above the masses; $(\mathrm{C})$ counts per fragment as a function of the $[\mathrm{Cu}(\mathrm{II})]_{\mathrm{O}} /[\mathrm{Cu}(\mathrm{I})]_{\mathrm{O}}$ ratio from ToF-SIMS. The counts for the fragments with increasing $m / z$ are shown from left to right starting with $\mathrm{m} / \mathrm{z} 27$ in orange (diagonally hatched), at $m / z 43$ in green (densely diagonally hatched), at $m / z 55$ in brown (diagonally hatched), at $\mathrm{m} / \mathrm{z} 58$ in blue (horizontally hatched), at $\mathrm{m} /$ $z 72$ in pink (vertically hatched) and for 1 monomer with the mass of $113 \mathrm{~m} / \mathrm{z}$ in black [Colour figure can be viewed at wileyonlinelibrary.com]

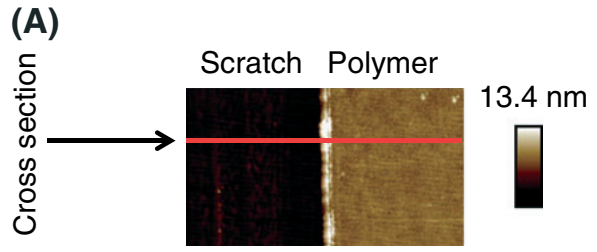

(B)

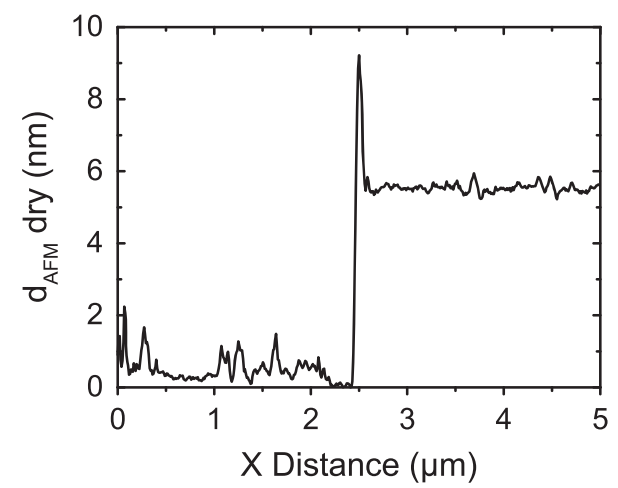

(C)

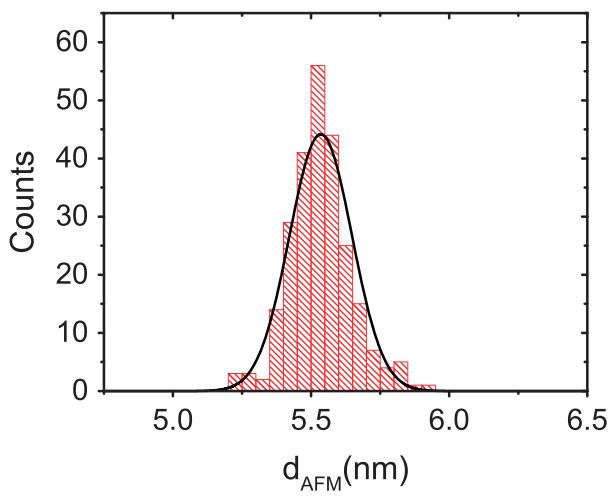

FIGURE 3 (A) AFM tapping mode height image of a dry PNIPAM brush layer on a silicon substrate fabricated at a $[\mathrm{Cu}(\mathrm{II})]_{0} /[\mathrm{Cu}(\mathrm{l})]_{0}$ ratio of $10 \%$. The horizontal scan size is $5 \mu \mathrm{m}$. The sample was scratched on the left-hand side to measure the step height from silicon substrate to the polymer film. The red line indicates the cross section for analyzing the step height, showed in (B); (C) histogram of the dry polymer thickness variation fitted with the Gaussian (black curve) [Colour figure can be viewed at wileyonlinelibrary.com]

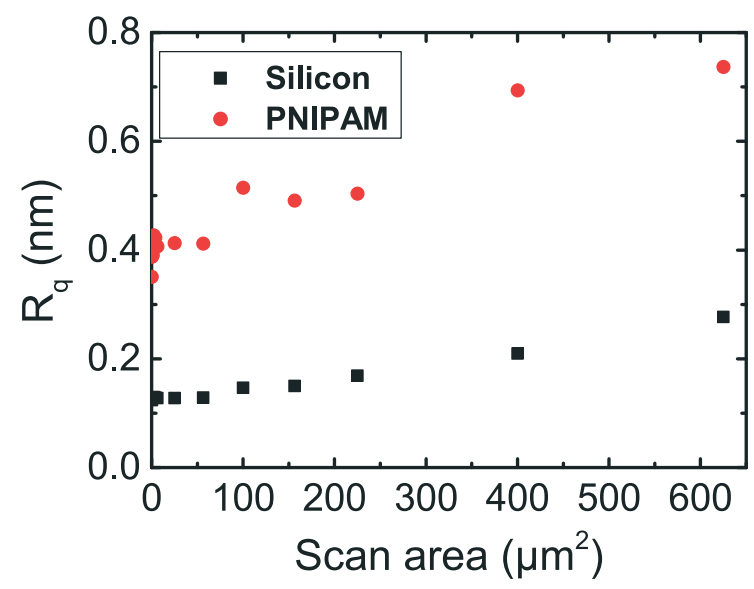

FIGURE 4 Root mean square roughness $\left(R_{q}\right)$ as function of scan area in $\mu \mathrm{m}^{2}$. The bare silicon substrate is compared with the polymer brush layer of PNIPAM. The $\mathrm{R}_{\mathrm{q}}$ for the silicon substrate and the polymer layer are plotted in black squares and red dots, respectively [Colour figure can be viewed at wileyonlinelibrary.com] 
may also result in lateral heterogeneities that can contribute to surface roughness.

\section{4 | Grafting density}

For a structural characterization of a polymer brush, the grafting density and the chain length are essential. For a direct chain length analysis, the polymer brush should be cleaved from the silicon substrate, eg, by using acid hydrolysis. ${ }^{55}$ The small amount of material can then be analyzed by GPC or by another direct molar mass analysis method ex situ. However, it is rather difficult to determine the grafting density for thin polymer layers grafted from the surfaces by conducting such a direct analysis, due to the fact that the amount of polymer chains is very small. Therefore, we estimate the grafting density of PNIPAM brushes from the swelling ratio between the dry and the swollen states, respectively. ${ }^{56}$ In a previous study, the force effect on a PNIPAM layer thickness was shown by performing force-volume measurements recorded in situ at several temperatures in the range 30 to $36^{\circ} \mathrm{C} .^{57}$ This required a precise thickness determination of the grafted layers. We note that the thickness obtained by AFM may strongly depend on the operating conditions, eg, set point and limited contact area (sharp nano-sized AFM tip), due to chain compression effects. Hence, we chose the contact mode imaging with a soft cantilever employed with a micro-sized colloid to minimize those drawbacks.

In Figure 5, we plot the wet thickness of a swollen polymer layer against the $\mathrm{x}$ distance. The black curves represent 8 cross sections

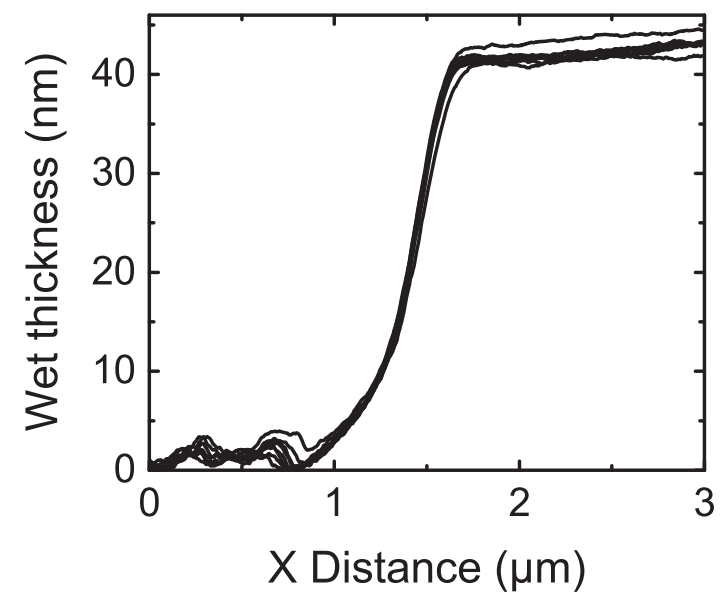

FIGURE 5 Cross-section profiles of a wet PNIPAM brush layer on a silicon substrate measured in contact mode AFM in water using a colloidal probe cantilever with $5-\mu \mathrm{m}$ PS bead. The wet thickness in $\mathrm{nm}$ is plotted against the $X$ distance in $\mu \mathrm{m}$. The sample was scratched to measure the step height from silicon to the swollen polymer film. Curves represent 8 cross sections taken along the scan area along the scan area. We observed, similar to AFM measurements in the dry state, an inhomogeneous scratching of the polymer layer. From the swelling experiments in water, we observed a highly stretched behavior of our PNIPAM chains compared with the thickness in dry state. The swollen polymer thickness was averaged for a scan size of $3 \mu \mathrm{m}$. The polymer layer thickness becomes significantly higher after adding the solvent (water) to the polymer films. We present 2 polymer substrates in the wet state, and we show the averaged wet thickness measured for 3 different spots per sample in Table 2 .

The grafting density was found to be between 0.11 and 0.19 chains per $\mathrm{nm}^{2}$ using the relation ${ }^{56}$

$$
h_{\text {wet }} / h_{\text {dry }}=1.03 / \sigma^{2 / 3}
$$

where $h_{\text {wet }}$ is the wet thickness, $h_{\text {dry }}$ the dry thickness, and $\sigma$ the grafting density. Independently of the first estimation of the grafting density, we calculated the grafting density based on the dry thickness via a different route. ${ }^{58,59}$ For a dry layer thickness of $6.3 \mathrm{~nm}$ and a molar mass of $8200 \mathrm{~g} / \mathrm{mol}$, we calculated a grafting density of 0.51 chains $/ \mathrm{nm}^{2}$ (0.36 chains $/ \mathrm{nm}^{2}$ for a dry thickness of $9.5 \mathrm{~nm}$, respectively). This confirms the estimation of the grafting density. The reduced tethered grafting density $\Sigma$ is defined as

$$
\Sigma \equiv \sigma \pi R_{g}^{2}
$$

where $R_{\mathrm{g}}$ is the radius of gyration, with $R_{\mathrm{g}}=0.17 \mathrm{~N}^{3 / 5}, 1,60$ with $\mathrm{N}$ the total number of monomers in a polymer brush chain. The density $\Sigma$ is used to judge whether the grafted polymer layer indeed fulfills the brush-like character of the grafted polymer film. Because sparse high molar mass chains can also yield thin dry PNIPAM films, it is crucial to determine the grafting density. In general, 3 regimes exist for polymer grafts. Firstly, the "mushroom" or weakly interacting regime $(\Sigma<1)$, secondly the "mushroom-to-brush" regime $(1<\Sigma<5)$, and thirdly the brush regime $(\Sigma>5)$. The "true brush" regime can be defined at significantly high stretching of the polymer chains that is typically $\Sigma>5$. We observed $\Sigma$ between 3 and 4.3 chains per area that a free non-overlapping polymer chain would occupy under the same temperature and solvent conditions. From this calculation, we conclude that our procedures lead to chains in the "mushroom-to-brush" transition regime. Finally, we note that for shorter reaction times of our procedure, the thickness at a given $[\mathrm{Cu}(\mathrm{II})]_{0} /[\mathrm{Cu}(\mathrm{I})]_{0}$ ratio would decrease. However, in this case, one would further shift the molar mass towards the mushroom regime.

\begin{tabular}{|c|c|c|c|c|c|}
\hline $\begin{array}{l}\text { Dry thickness (nm, } \\
\text { tapping mode AFM) }\end{array}$ & $\begin{array}{l}\text { Wet thickness (nm, } \\
\text { colloidal probe AFM) }\end{array}$ & $\begin{array}{l}\text { Grafting density } \\
\text { chains } / \mathrm{nm}^{2}\end{array}$ & Molar mass, $\mathrm{g} / \mathrm{mol}$ & $\begin{array}{l}\text { Radius of } \\
\text { gyration (nm) }\end{array}$ & $\begin{array}{l}\text { Reduced grafting } \\
\text { density } \Sigma\end{array}$ \\
\hline $6.3 \pm 0.3^{a}$ & $19.5 \pm 1.1^{\mathrm{a}}$ & 0.19 & b8.2 k & 2.2 & 3 \\
\hline $9.5 \pm 0.3$ & $41.7 \pm 1.7$ & 0.11 & $17.6 \mathrm{k}$ & 3.5 & 4.3 \\
\hline
\end{tabular}

TABLE 2 Swelling ratio of PNIPAM brushes as a function of their layer thickness

${ }^{a}$ Calculated as 1 standard deviation from AFM image analysis.

${ }^{b}$ Calculated by assuming a completely stretched polymer chain. 


\section{4 | CONCLUSIONS}

We have demonstrated a reproducible procedure to graft ultra-thin PNIPAM layers from silicon by varying the $[\mathrm{Cu}(\mathrm{II})]_{0} /[\mathrm{Cu}(\mathrm{I})]_{0}$ ratio. The results show that our approach leads to grafts in the "mushroom-tobrush" transition regime. The grafted layers we describe here can be employed in surface functionalization in applications where a distance confined by a thickness is explored, such as precisely positioning light emitters at the exterior surface of the brush from the underlying substrate.

\section{ACKNOWLEDGEMENTS}

This work was supported by the Netherlands Organisation for Scientific Research NWO (Dutch: Nederlandse Organisatie voor Wetenschappelijk Onderzoek). We thank Lars Birlenbach from the University Siegen for the ToF-SIMS measurements, Krzysztof Matyjaszewski for fruitful discussions during his visits to Twente, Sissi de Beer, Michel KleinGunnewiek, Edmondo Benetti, Maciek Kopec, and Ad Lagendijk for their support and numerous discussions.

\section{CONFLICT OF INTEREST}

The authors declare no competing financial interests.

\section{ORCID}

Andreas S. Schulz (D) http://orcid.org/0000-0001-7703-5111

\section{REFERENCES}

1. Wu T, Efimenko K, Genzer J. Combinatorial study of the mushroom-tobrush crossover in surface anchored polyacrylamide. J Am Chem Soc. 2002;124(32):9394-9395.

2. Edmondson S, Osborne VL, Huck WTS. Polymer brushes via surfaceinitiated polymerizations. Chem Soc Rev. 2004;33(1):14-22.

3. Rühe J, Ballauff $M$, Biesalski $M$, et al. Polyelectrolyte brushes. In: Schmidt M, ed. Polyelectrolytes with Defined Molecular Architecture I. Berlin, Heidelberg: Springer Berlin Heidelberg; 2004:79-150.

4. Matyjaszewski K, Dong $H$, Jakubowski W, Pietrasik J, Kusumo A Grafting from surfaces for "everyone": ARGET ATRP in the presence of air. Langmuir. 2007;23(8):4528-4531.

5. Barbey R, Lavanant L, Paripovic D, et al. Polymer brushes via surfaceinitiated controlled radical polymerization: synthesis, characterization, properties, and applications. Chem Rev. 2009;109(11):5437-5527.

6. Stuart MAC, Huck WTS, Genzer J, et al. Emerging applications of stimuli-responsive polymer materials. Nat Mat. 2010;9(2):101-113.

7. Wunder S, Polzer F, Lu Y, Mei Y, Ballauff M. Kinetic analysis of catalytic reduction of 4-nitrophenol by metallic nanoparticles immobilized in spherical polyelectrolyte brushes. J Phys Chem C. 2010;114(19):8814-8820.

8. Groll J, Amirgoulova EV, Ameringer T, et al. Biofunctionalized, ultrathin coatings of cross-linked star-shaped poly(ethylene oxide) allow reversible folding of immobilized proteins. J Am Chem Soc. 2004;126(13):4234-4239.

9. Brantley EL, Holmes TC, Jennings GK. Modification of ATRP surfaceinitiated poly(hydroxyethyl methacrylate) films with hydrocarbon side chains. J Phys Chem B. 2004;108(41):16077-16084.

10. Faulkner CJ, Fischer RE, Jennings GK. Surface-initiated polymerization of 5-(perfluoro-n-alkyl)norbornenes from gold substrates. Macromolecules. 2010;43(3):1203-1209.
11. Balboni I, Limb C, Tenenbaum JD, Utz PJ. Evaluation of microarray surfaces and arraying parameters for autoantibody profiling. Proteomics. 2008;8(17):3443-3449.

12. Iwata R, Satoh R, Iwasaki Y, Akiyoshi K. Covalent immobilization of antibody fragments on well-defined polymer brushes via site-directed method. Colloid Surface B. 2008;62(2):288-298.

13. Raynor JE, Capadona JR, Collard DM, Petrie TA, García AJ. Polyme brushes and self-assembled monolayers: versatile platforms to control cell adhesion to biomaterials (Review). Biointerphases. 2009;4(2): FA3-FA16.

14. Shenhar R, Norsten TB, Rotello VM. Polymer-mediated nanoparticle assembly: structural control and applications. Adv Mater. 2005;17(6):657-669

15. Novotny L, Hecht B. Principles of Nano-optics. Principles of nano-optics. 2006.

16. Nikolaev IS, Vos WL, Koenderink AF. Accurate calculation of the local density of optical states in inverse-opal photonic crystals. J Opt Soc Am B. 2009;26(5):987-997.

17. Wubs M, Vos WL. Förster resonance energy transfer rate in any dielectric nanophotonic medium with weak dispersion. New J Phys. 2016;18(5): 053037

18. Heskins M, Guillet JE. Solution properties of $\operatorname{poly}(\mathrm{N}$ isopropylacrylamide). J Macromol Sci A. 1968;2(8):1441-1455.

19. Masci G, Giacomelli L, Crescenzi V. Atom transfer radical polymerization of N-isopropylacrylamide. Macromol Rapid Commun. 2004;25(4): 559-564.

20. Matyjaszewski K, Miller PJ, Shukla N, et al. Polymers at interfaces: using atom transfer radical polymerization in the controlled growth of homopolymers and block copolymers from silicon surfaces in the absence of untethered sacrificial initiator. Macromolecules. 1999;32(26):8716-8724.

21. Kato M, Kamigaito M, Sawamoto M, Higashimura T. Polymerization of methyl methacrylate with the carbon tetrachloride/dichlorotris(triphenylphosphine)ruthenium(II)/methylaluminum Bis(2,6-di-tertbutylphenoxide) initiating system: possibility of living radical polymerization. Macromolecules. 1995;28(5):1721-1723.

22. Wang J-S, Matyjaszewski K. Controlled/"living" radical polymerization. atom transfer radical polymerization in the presence of transition-metal complexes. J Am Chem Soc. 1995;117(20):5614-5615.

23. Börner HG, Beers K, Matyjaszewski K, Sheiko SS, Möller M. Synthesis of molecular brushes with block copolymer side chains using atom transfer radical polymerization. Macromolecules. 2001;34(13):43754383.

24. Kamigaito M, Ando T, Sawamoto M. Metal-catalyzed living radical polymerization. Chem Rev. 2001;101(12):3689-3746.

25. Gao H, Matyjaszewski K. Synthesis of molecular brushes by "grafting onto" method: combination of ATRP and click reactions. J Am Chem Soc. 2007;129(20):6633-6639.

26. Sheiko SS, Sumerlin BS, Matyjaszewski K. Cylindrical molecular brushes: synthesis, characterization, and properties. Prog Polym Sci. 2008;33(7):759-785.

27. Yamamoto S-I, Pietrasik J, Matyjaszewski K. Temperature- and $\mathrm{pH}$ responsive dense copolymer brushes prepared by ATRP. Macromolecules. 2008;41(19):7013-7020.

28. Ouchi M, Terashima T, Sawamoto M. Transition metal-catalyzed living radical polymerization: toward perfection in catalysis and precision polymer synthesis. Chem Rev. 2009;109(11):4963-5050.

29. Ye J, Narain R. Water-assisted atom transfer radical polymerization of $\mathrm{N}$-isopropylacrylamide: nature of solvent and temperature. Journal of Physical Chemistry B. 2009;113(3):676-681.

30. Zhang H, Klumperman B, Ming W, Fischer H, van der Linde R. Effect of $\mathrm{Cu}(\mathrm{II})$ on the kinetics of the homogeneous atom transfer radical polymerization of methyl methacrylate. Macromolecules. 2001;34(18): 6169-6173. 
31. Patten TE, Matyjaszewski K. Atom transfer radical polymerization and the synthesis of polymeric materials. Adv Mater. 1998;10(12):901-915.

32. Ricka J, Tanaka T. Phase transition in ionic gels induced by copper complexation. Macromolecules. 1985;18(1):83-85.

33. Teodorescu M, Matyjaszewski K. Atom transfer radical polymerization of (meth)acrylamides. Macromolecules. 1999;32(15):4826-4831.

34. Teodorescu M, Matyjaszewski K. Controlled polymerization of (meth) acrylamides by atom transfer radical polymerization. Macromol Rapid Commun. 2000;21(4):190-194

35. Kizhakkedathu JN, Norris-Jones R, Brooks DE. Synthesis of welldefined environmentally responsive polymer brushes by aqueous ATRP. Macromolecules. 2004;37(3):734-743.

36. Fulghum TM, Estillore NC, Vo C-D, Armes SP, Advincula RC. Stimuliresponsive polymer ultrathin films with a binary architecture: combined layer-by-layer polyelectrolyte and surface-initiated polymerization approach. Macromolecules. 2008;41(2):429-435.

37. Alem H, Duwez A-S, Lussis P, Lipnik P, Jonas AM, Demoustier-Champagne $\mathrm{S}$. Microstructure and thermo-responsive behavior of $\operatorname{poly}(\mathrm{N}$ isopropylacrylamide) brushes grafted in nanopores of track-etched membranes. J Membr Sci. 2008;308(1-2):75-86.

38. Malham IB, Bureau L. Density effects on collapse, compression, and adhesion of thermoresponsive polymer brushes. Langmuir. 2010;26(7):4762-4768

39. Cimen D, Caykara T. Preparation of oligo-N-isopropylacrylamide brushes with $-\mathrm{OH}$ and $-\mathrm{COOH}$ end-groups via surface-initiated NMP. J Appl Polym Sci. 2013;129(1):383-390.

40. Pomorska A, Wolski K, Puciul-Malinowska A, Zapotoczny S. Tailored conditions for controlled and fast growth of surface-grafted PNIPAM brushes. Polymer. 2016;97:380-386.

41. Sui X, Zapotoczny S, Benetti EM, Schon P, Vancso GJ. Characterization and molecular engineering of surface-grafted polymer brushes across the length scales by atomic force microscopy. J Mater Chem. 2010;20(24):4981-4993.

42. Plunkett KN, Zhu X, Moore JS, Leckband DE. PNIPAM chain collapse depends on the molecular weight and grafting density. Langmuir. 2006;22(9):4259-4266

43. Hutter JL, Bechhoefer J. Calibration of atomic-force microscope tips. Review of Scientific Instruments. 1993;64(7):1868-1873.

44. Sader JE, Larson I, Mulvaney P, White LR. Method for the calibration of atomic force microscope cantilevers. Review of Scientific Instruments. 1995;66(7):3789-3798.

45. Kostruba A, Stetsyshyn Y, Vlokh R. Method for determination of the parameters of transparent ultrathin films deposited on transparent substrates under conditions of low optical contrast. Appl Optics. 2015;54(20):6208-6216.

46. Benninghoven A. Chemical analysis of inorganic and organic surfaces and thin films by static time-of-flight secondary ion mass spectrometry (TOF-SIMS). Angewandte Chemie International Edition in English. 1994:33(10):1023-1043.

47. Bulle-Lieuwma CWT, van Gennip WJH, van Duren JKJ, Jonkheijm P, Janssen RAJ, Niemantsverdriet JW. Characterization of polymer solar cells by TOF-SIMS depth profiling. Appl Surf Sci. 2003;203-204:547550.

48. Pasche S, De Paul SM, Vörös J, Spencer ND, Textor M. Poly(I-lysine)graft-poly(ethylene glycol) assembled monolayers on niobium oxide surfaces: a quantitative study of the influence of polymer interfacial architecture on resistance to protein adsorption by ToF-SIMS and in situ OWLS. Langmuir. 2003;19(22):9216-9225.

49. Schilke KF, McGuire J. Detection of nisin and fibrinogen adsorption on poly(ethylene oxide) coated polyurethane surfaces by time-of-flight secondary ion mass spectrometry (TOF-SIMS). J Colloid Interface Sci. 2011;358(1):14-24.

50. Cheng X, Canavan HE, Stein MJ, et al. Surface chemical and mechanical properties of plasma polymerized $\mathrm{N}$-isopropylacrylamide. Langmuir: the ACS journal of surfaces and colloids. 2005;21(17):7833-7841.

51. Heinz P, Brétagnol F, Mannelli I, et al. Poly( $\mathrm{N}$-isopropylacrylamide) grafted on plasma-activated poly(ethylene oxide): thermal response and interaction with proteins. Langmuir. 2008;24(12):6166-6175.

52. Cole MA, Jasieniak M, Thissen H, Voelcker NH, Griesser HJ. Time-offlight-secondary ion mass spectrometry study of the temperature dependence of protein adsorption onto poly $(\mathrm{N}$-isopropylacrylamide) graft coatings. Anal Chem. 2009;81(16):6905-6912.

53. Chen M, Dong M, Havelund R, et al. Thermo-responsive core-sheath electrospun nanofibers from poly ( $\mathrm{N}$-isopropylacrylamide)/ polycaprolactone blends. Chem Mater. 2010;22(14):4214-4221.

54. Stetsyshyn Y, Zemla J, Zolobko O, et al. Temperature and $\mathrm{pH}$ dualresponsive coatings of oligoperoxide-graft-poly( $\mathrm{N}$-isopropylacrylamide): wettability, morphology, and protein adsorption. J Colloid Interface Sci. 2012;387(1):95-105

55. Cummings C, Murata H, Koepsel R, Russell AJ. Tailoring enzyme activity and stability using polymer-based protein engineering. Biomaterials. 2013;34(30):7437-7443.

56. Wang S, Zhu Y. Facile method to prepare smooth and homogeneous polymer brush surfaces of varied brush thickness and grafting density. Langmuir. 2009;25(23):13448-13455.

57. Benetti EM, Zapotoczny S, Vancso GJ. Tunable thermoresponsive polymeric platforms on gold by "photoiniferter"-based surface grafting. Adv Mater. 2007;19(2):268-271.

58. Stetsyshyn Y, Raczkowska J, Budkowski A, et al. Synthesis and postpolymerization modification of thermoresponsive coatings based on pentaerythritol monomethacrylate: surface analysis, wettability, and protein adsorption. Langmuir. 2015;31(35):9675-9683.

59. Raczkowska J, Stetsyshyn Y, Awsiuk K, et al. Temperature-responsive properties of poly(4-vinylpyridine) coatings: influence of temperature on the wettability, morphology, and protein adsorption. RSC Adv. 2016;6(90):87469-87477.

60. Brittain WJ, Minko S. A structural definition of polymer brushes. $J$ Polym Sci A Polym Chem. 2007:45(16):3505-3512.

\section{SUPPORTING INFORMATION}

Additional Supporting Information may be found online in the supporting information tab for this article.

How to cite this article: Schulz AS, Gojzewski H, Huskens J, Vos WL, Julius Vancso G. Controlled sub-10-nanometer poly( $\mathrm{N}$-isopropyl-acrylamide) layers grafted from silicon by atom transfer radical polymerization. Polym Adv Technol. 2018;29:806-813. https://doi.org/10.1002/pat.4187 